\title{
Elevated microRNA-125b levels predict a worse prognosis in HER2-positive breast cancer patients
}

\author{
YANWEI LUO ${ }^{1-3^{*}}$, XINYE WANG ${ }^{1,2^{*}}$, WEIHONG NIU ${ }^{1,2}$, HERAN WANG $^{1,2}$, QIUYUAN WEN $^{4}$, \\ SONGQING FAN ${ }^{4}$, RAN ZHAO ${ }^{1,2}$, ZHENG LI $^{1,2}$, WEI XIONG ${ }^{1,2}$, SHUPING PENG ${ }^{1,2}$, ZHAOYANG ZENG ${ }^{1,2}$, \\ XIAOLING LI ${ }^{1,2}$, GUIYUAN LI ${ }^{1,2}$, MING TAN ${ }^{5}$ and MING ZHOU ${ }^{1,2}$ \\ ${ }^{1}$ Cancer Research Institute, Central South University; ${ }^{2}$ Key Laboratory of Carcinogenesis, Ministry of Health, Changsha, \\ Hunan 410078; ${ }^{3}$ Department of Transfusion, The Third Xiang-Ya Hospital, Central South University, Changsha, \\ Hunan 410013; ${ }^{4}$ Department of Pathology, The Second Xiang-Ya Hospital, Central South University, Changsha, \\ Hunan 410011, P.R. China; ${ }^{5}$ Mitchell Cancer Institute, University of South Alabama, Mobile, AL 36604, USA
}

Received July 8, 2015; Accepted October 7, 2016

DOI: $10.3892 / \mathrm{ol} .2016 .5482$

\begin{abstract}
Breast cancer, the second most common cancer worldwide, is the leading cause of cancer-associated mortality in women, accounting for $\sim 15 \%$ of all cancer-associated mortalities in women. The development, local invasion and metastasis of breast cancer are associated with the dysregulation and mutation of numerous genes and epigenetic mechanisms, including coding RNA and non-coding RNA, such as microRNAs (miRs/miRNAs). Previous studies have shown a dual-faced role of miR-125b in breast cancer. In the present study, a total of 221 paraffin-embedded breast cancer and 49 paraffin-embedded non-cancerous breast tissue samples were collected. In situ hybridization was used to analyze the expression of miR-125b in the breast cancer tissues. Spearman's rank correlation analysis was used to analyze the expression correlation between miR-125b and human epidermal growth factor 2 (HER2). The overall survival estimates over time were calculated using the Kaplan-Meier method with log-rank test. It was found that miR-125b expression was significantly increased in the breast cancer tissues compared with that in the non-cancerous tissues, and high miR-125b expression indicated a poor prognosis in the breast cancer patients. In addition, miR-125b expression was positively correlated with HER2, but not with progesterone receptor and estrogen receptor. Notably, high miR-125b expression was significantly correlated with tumor size and
\end{abstract}

Correspondence to: Dr Ming Zhou, Cancer Research Institute, Central South University, 110 Xiangya Road, Changsha, Hunan 410078, P.R. China

E-mail: zhouming2001@163.com

Dr Ming Tan, Mitchell Cancer Institute, University of South Alabama, 1660 Spring Hill Avenue, Mobile, AL 36604, USA

E-mail:mtan@health.southalabama.edu

*Contributed equally

Key words: breast cancer, miR-125b, HER2, prognosis, paclitaxel
Tumor-Node-Metastasis stage in the HER2-positive breast cancer patients, along with a poor prognosis. The present study provides clinical data to confirm the oncogenic potential of miR-125b, particularly in HER2-positive human breast cancer. Thus, identification of miR-125b may be a potential molecular biomarker for the prediction of clinical outcomes in breast cancer patients, particularly HER2-positive cases that will receive paclitaxel-based neoadjuvant chemotherapy.

\section{Introduction}

Breast cancer is the second most common cancer worldwide and is the leading cause of cancer-associated mortality in women, accounting for $\sim 15 \%$ of all cancer-associated mortalities in women (1). Breast cancer is heterogeneous and can be classified into several subtypes, including luminal, human epidermal growth factor 2 (HER2) and triple-negative breast cancer (TNBC) subtypes, based on the expression of estrogen receptor (ER) and progesterone receptor $(\mathrm{PR})$ and the receptor tyrosine kinase erbB-2 (HER2) $(2,3)$. Thus, it is important to understand the molecular mechanisms involved in the development and the acquisition of malignancy in breast tumor, and develop more effective treatments for breast cancer patients.

The development, local invasion or metastasis of breast cancer is involved in the dysregulation, mutation and epigenetic mechanism of various genes (4). The dysregulated genes include coding RNA and non-coding RNA, such as microRNAs (miRNAs) (5). miRNAs are able to silence gene expression by targeting complementary regions of mRNAs and inhibiting protein translation, which is critical in normal and abnormal biological processes, including cancer (6). Dysregulation of miRNAs has been observed in breast cancer and is associated with tumor growth, drug resistance and metastasis (7). Therefore, therapeutic strategies based on modulating the expression levels of miRNAs are promising approaches for breast cancer treatment.

miR-125b is dysregulated in a variety of tumors; however, as miR-125b is either upregulated or downregulated in different tumors, this suggests that the oncogenic and tumor suppressive potential of miR-125b is dependent on the type 
of cancers (8). In addition, previous studies have shown a different role of miR-125b in breast cancer. Ferracin et al found a downregulation of miR-125b in metastatic breast cancers (9), which may account for hypermethylation of the miR-125b promoter (10). Feliciano et al found that miR-125b acted as a tumor suppressor in breast tumorigenesis via its direct targets glutamyl amino peptidase, casein kinase II- $\alpha$, cyclin-J and multiple epidermal growth factor-like domains 9 (11). In addition, miR-125b-overexpressing breast cancer cells were impaired in their anchorage-dependent growth and exhibited reduced migration and invasion capacities (12). However, miR-125b can also induce metastasis by targeting StAR related lipid transfer domain containing 13 (STARD13) in MCF-7 and MDA-MB-231 breast cancer cells (13). Our previous study demonstrated that upregulation of miR-125b conferred a chemoresistant phenotype by targeting B-cell lymphoma 2 antagonist killer 1 (Bak1) (14), and other previous data showed that miR-125b could maintain cancer stem-like side population fraction (15). Circulating miR-125b expression was associated with chemotherapeutic resistance of breast cancer (16). Due to these different arguments, the role of miR-125b in breast cancer requires additional studying.

In the present study, the expression of miR-125b and clinicopathological correlation in breast cancer tissues was investigated by in situ hybridization (ISH). The association between miR-125b expression and the molecular subtype of breast cancer was analyzed. It was found that miR-125b expression is elevated in breast cancer tissues compared to that in non-cancerous tissues, and associated with clinical tumor node-metastasis (TNM) stages, predicting a poor prognosis. In addition, miR-125b expression is positively correlated with HER2 expression and significantly associated with the tumor size, lymph node metastasis status and TNM stage in HER2-positive breast cancer patients. The current study provides clinical data to demonstrate the oncogenic potential of miR-125b, particularly in HER2-positive human breast cancer. miR-125b may be a good prognostic marker combined with HER2 in human breast cancer.

\section{Materials and methods}

Tissue samples and clinical data. In total, 221 paraffin-embedded breast cancer and 49 paraffin-embedded non-cancerous breast tissue samples obtained between November 2001 and September 2012 at The Second Xiangya Hospital of Central South University (Changsha, China) were used. All the tissue samples were formed into 9 slices in a tissue microarray, as previously described (17), with each sample in duplicate or triplicate. Clinicopathological characteristics of breast cancer patients were recorded including name, gender, age, occupation, ethnicity, clinical TNM stage, recurrence, pathology diagnosis, molecular subtype and chemoradiotherapy strategies. All the patient information was anonymized prior to analysis. The profile of clinicopathological characteristics of the breast cancer patients is shown in Table I. The age of patients ranged between 23 and 71 years. All 221 patients with breast cancer had valid follow-up data, of which 30 cases had used therapeutic strategies containing paclitaxel. The overall survival (OS) was defined as the time between diagnosis and the date of death or the date last known alive. The present study was approved by the Committee on the Ethics of Central South University. All individuals participating or their families provided written informed consent.

$I S H$. The ISH probe used for detecting miR-125b labeled digoxin was designed and synthesized by Sangon Biotech Co., Ltd. (Shanghai, China). Slices were processed using Enhanced Sensitive ISH Detection kit I (catalogue no., MK1030; Wuhan Boster Biological Technology, Ltd., Wuhan, China) according to the manufacturer's protocol. The kit contains prehybridization solution, normal goat serum, biotin-antidigoxin IgG, streptavidin-biotin-complex and biotin-peroxidase. Slides were deparaffinized and hydrated with xylene twice (each for $10 \mathrm{~min})$, put through an ethanol gradient $(100,95,90,80$ and $70 \%$, each for $5 \mathrm{~min}$ ), and rinsed with distilled water $\left(\mathrm{dH}_{2} \mathrm{O}\right)$. The slides then were treated with $3 \% \mathrm{H}_{2} \mathrm{O}_{2}$ for $15 \mathrm{~min}$ and washed twice with $\mathrm{dH}_{2} \mathrm{O}$. The slides were then treated with pepsin solution for $10 \mathrm{~min}$ at $37^{\circ} \mathrm{C}$, and washed three times with $0.5 \mathrm{M}$ phosphate-buffered saline (PBS) for $5 \mathrm{~min}$ and once with $\mathrm{dH}_{2} \mathrm{O}$ for $10 \mathrm{~min}$ at room temperature. Following $3 \mathrm{~h}$ incubation with prehybridization solution at $37^{\circ} \mathrm{C}$, slides were incubated with miR-125b probe $(2 \mu \mathrm{g} / \mathrm{ml}$; Sangon Biotech Co., Ltd.) overnight at $55^{\circ} \mathrm{C}$. On the next day, slides were incubated in $2 \mathrm{X}$ saline sodium citrate (SSC) for $30 \mathrm{~min}$ at $37^{\circ} \mathrm{C}$, washed once with $0.5 \mathrm{X} \mathrm{SSC}$ for $15 \mathrm{~min}$, and then washed 3 times with $0.2 \mathrm{X}$ SSC for $10 \mathrm{~min}$. Following $30 \mathrm{~min}$ blockade with normal goat serum at $37^{\circ} \mathrm{C}$, slices were incubated with biotin-antidigoxin $\mathrm{IgG}$ for $90 \mathrm{~min}$ at $37^{\circ} \mathrm{C}$ and washed 4 times with $0.5 \mathrm{M}$ PBS for $5 \mathrm{~min}$, followed by Streptavidin-Biotin-Complex and biotin-peroxidase incubation for $30 \mathrm{~min}$ at $37^{\circ} \mathrm{C}$. Subsequent to washing in $0.5 \mathrm{M}$ PBS for $20 \mathrm{~min}$, the slides were visualized with 3,3'-diaminobenzidine (Fuzhou Maixin Biotech Co., Ltd., Fuzhou, China) for $5 \mathrm{~min}$ and counterstained with hematoxylin for $90 \mathrm{sec}$. The slides were mounted and dried. Images of slides were captured with an Olympus BX51 microscope (magnification, x200; Olympus Corporation, Tokyo, Japan).

Evaluation of staining. The slides were evaluated by two independent pathologists under a light microscope (magnification, x200; BX51; Olympus Corporation). miR-125b staining intensity was scored as 0 (no staining was determined as negative, -), 1 (light yellow staining was determined as weak, + ), 2 (yellow staining was determined as moderate, ++ ) and 3 (tan staining was determined as strong, +++ ). The extent of staining was scored as $0-1.0(0-100 \%)$. The final staining score (0-3) was calculated as the multiplication of the intensity score and extent score. The expression of miR-125b was scored as high expression $(\geq 1)$ or low expression $(<1)$. To compare the expression of miR-125b between normal and tumor tissues, the score of miR-125b expression was normalized to the average score of miR-125b in normal tissues.

Statistical analysis. GraphPad Prism 5 software (Graphpad Software, Inc., La Jolla, CA, USA) was used to perform statistical analysis. The data are presented as the mean \pm standard deviation. The difference of miR-125b expression between breast cancer and non-cancerous breast tissue was analyzed using Student's $t$-test. The correlation between miR-125b expression and HER2 expression was analyzed using Spearman's rank correlation analysis. The contingency data was 
analyzed by using $\chi^{2}$ or Fisher's exact test. The OS estimates over time were calculated using the Kaplan-Meier method with log-rank test. A value of $\mathrm{P}<0.05$ was considered to indicate a statistically significant difference.

\section{Results}

Association between the expression of miR-125b and clinicopathological features of breast cancer. The present study detected the expression of miR-125b in breast cancer and non-cancerous breast control tissue by ISH. Expression of the miR-125b was found in the cytoplasm and nucleus of breast cancer cells (Fig. 1A). The percentage of high miR-125b expression in the breast cancer and the noncancerous breast control tissue was $68.3 \%(151 / 221)$ and $57.1 \%$ (28/49) respectively. There was a significantly higher score of the miR-125b expression in breast cancer compared to that of non-cancerous breast control tissue ( $\mathrm{P}=0.0005)$ (Fig. 1B).

The current study additionally investigated the association between the expression of the miR-125b and clinicopathological features of breast cancer including age, gender, tumor size, lymph node metastasis status, distant metastasis, and clinical TNM stage in a univariate $\chi^{2}$ test. As shown in Table II, no significant differences were observed between miR-125b expression and age, gender, tumor size, lymph node metastasis status or distant metastasis of breast cancer $(\mathrm{P}>0.05)$. However, miR-125b expression was significantly associated with the clinical TNM stage $(\mathrm{P}=0.02)$.

High miR-125b expression has a poor prognosis in HER2-positive breast cancer patients. As shown in Table II, although no significant correlation was identified between the expression of miR-125b and expression of ER and PR ( $>>0.05)$, there was a significant association between expression of miR-125b and HER 2 in breast cancer patients $(\mathrm{P}=0.034)$. In addition, the expression of miR-125b was positively correlated with the HER2 expression ( $\mathrm{r}=0.4, \mathrm{P}<0.001$; Fig. $2 \mathrm{~A}$ and $\mathrm{B}$ ).

The present study additionally analyzed the association between miR-125b expression and clinical outcomes. All 221 breast cancer patients were included in the survival curves. The median OS time was 40 months, with a range of 2-124 months. The OS rate of patients with high miR-125b expression was significantly decreased compared to the survival of patients with low miR-125b expression $(\mathrm{P}=0.038$; hazard ratio, 0.55 ; 95\% CI, 0.31-0.96; Fig. 3A). To investigate the association between miR-125b and molecular subtypes of breast cancer, all 221 breast cancer cases were classified into the following groups: Luminal (high miR-125b expression, $\mathrm{n}=81$; low miR-125b expression, $\mathrm{n}=38$ ), identified as $\mathrm{ER}^{+}$and/or $\mathrm{PR}^{+}$; HER2 (high miR-125b expression, $\mathrm{n}=51$; low miR-125b expression, $\mathrm{n}=20$ ), identified as ER/PR ${ }^{-}$and $\mathrm{HER} 2^{+}$; and TNBC (high miR-125b expression, $n=19$; low miR-125b expression, $\mathrm{n}=12$ ), identified as ER/PR ${ }^{-}$and HER2- (18). There was no significant difference between the OS rate of patients with high miR-125b expression and that of patients with low miR-125b expression in the molecular luminal (Fig. 3B) and TNBC (Fig. 2D) subtypes. Notably, the OS rate of patients with high miR-125b expression was significantly reduced compared to the survival of patients with low miR-125b expression in molecular subtypes of HER2 $(\mathrm{P}=0.02$; hazard
Table I. Clinicopathological characteristics of breast cancer patients.

\begin{tabular}{lc}
\hline Characteristic & Value, $\%(\mathrm{n})$ \\
\hline Age, mean \pm SD & $46 \pm 0.66$ \\
Gender & \\
Male & $0.4(1 / 221)$ \\
Female & $99.6(220 / 221)$ \\
Tumor size & \\
T1-2 & $57.0(126 / 221)$ \\
T3-4 & $43.0(95 / 221)$ \\
Nodal metastasis & \\
Present & $77.8(172 / 221)$ \\
Absent & $22.2(49 / 221)$ \\
Distant metastasis & \\
Present & $11.8(26 / 221)$ \\
Absent & $88.2(195 / 221)$ \\
TNM stage & \\
I & $5.9(13 / 221)$ \\
II & $58.8(130 / 221)$ \\
III & $24.4(54 / 221)$ \\
IV & $10.9(24 / 221)$ \\
\hline
\end{tabular}

SD, standard deviation; TNM, tumor-node-metastasis.

ratio, 0.38; 95\% CI 0.16-0.92; Fig. 3C), indicating an association between miR-125b and HER2 receptor expression. Thus, the current study additionally analyzed the association between the expression of miR-125b and clinicopathological features of HER2-positive breast cancer. A total of 143 patients withHER2-positive breast cancer were included. As shown in Table III, no significant differences were observed between expression of miR-125b and age, gender and distant metastasis of HER2-positive breast cancer patients $(\mathrm{P}>0.05)$. However, miR-125b expression was significantly associated with the tumor size $(\mathrm{P}=0.03)$, lymph node metastasis status $(\mathrm{P}=0.03)$ and TNM stage $(\mathrm{P}=0.02)$.

High miR-125b expression predicts a poor prognosis in breast cancer patients treated with paclitaxel. To investigate the association between miR-125b and paclitaxel treatment in breast cancer, among the 221 breast cancer patients, 30 cases that used therapeutic strategies containing paclitaxel were included. As shown in Fig. 4, high miR-125b expression indicated a lower OS rate in patients treated with paclitaxel compared with those of patients with low miR-125b expression $(\mathrm{P}=0.041$; hazard ratio, 0.23 ; 95\% CI, 0.06-0.95; Fig. 4).

\section{Discussion}

miR-125b is located at chromosome 11q24 and chromosome 21q21, the so-called fragile sites, which are commonly deleted in lung, ovary and cervical cancer, indicating a functional loss of miR-125b in these tumor types (19). It has been demonstrated that miR-125b is dysregulated in a broad variety of tumors. It 
A

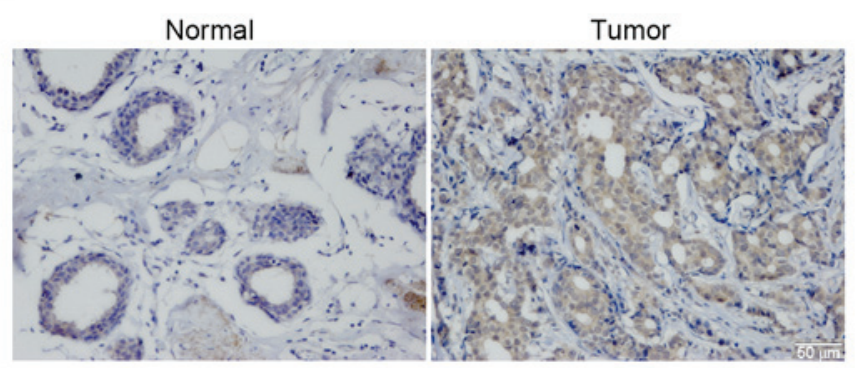

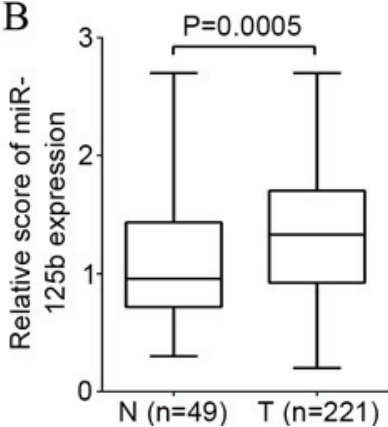

Figure 1. Evaluation of miR-125b expression in breast cancer and non-cancerous breast control tissues. (A) Representative images of miR-125b expression in non-cancerous and tumor tissues. The expression of miR-125b in breast cancer was significantly higher than in the non-cancerous breast control tissues. Scale bar, $50 \mu \mathrm{m}$. (B) Relative score of miR-125b expression in breast cancer and non-cancerous breast control tissue. $\mathrm{N}$, non-cancerous; $\mathrm{T}$, tumor tissue; $\mathrm{n}$, number of cases; miR, microRNA.

A
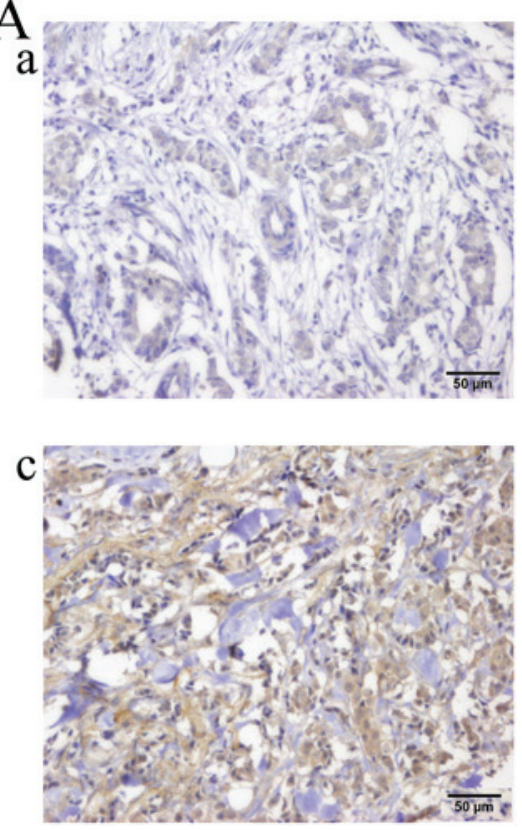


B

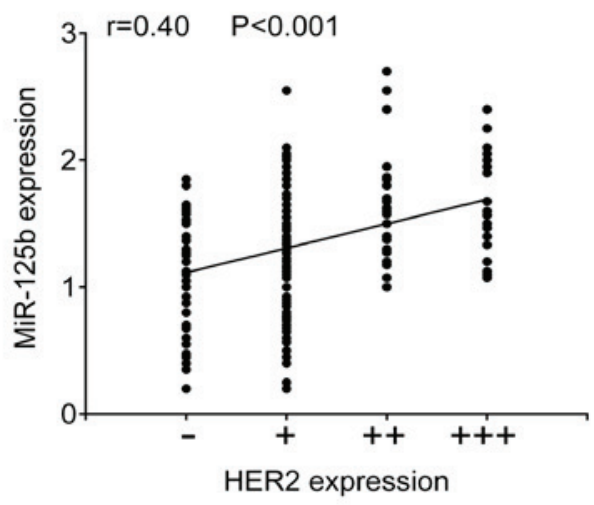

Figure 2. miR-125b was positively correlated with HER2 expression in breast cancer. (A) Representative images of miR-125b expression in (a) HER2 negative $(-),($ b) weak (+), (c) moderate (++) and (d) strong (+++) breast cancer tissues. Scale bar, $50 \mu$ m. (B) Spearman's correlation analysis was used to analyze the correlation between miR-125b and HER2 in breast cancer. $r=0.40, \mathrm{P}<0.001$. HER2, human epidermal growth factor 2; miR, microRNA.

is downregulated in head and neck tumors, oral squamous cell carcinomas, osteosarcomas and gliomas (20-23). Hypermethylation in the promoter regions of miR-125b appears to block miR-125b expression levels in ovarian cancer (24) and breast cancer (10). However, enhanced miR-125b expression was also observed in colorectal cancer, leukemia, gastric, follicular and pancreatic cancers and certain brain tumor-derived glioma cell lines, which are associated with poor prognoses (25-28). In the present study, it was found that miR-125b expression was significantly increased in breast cancer tissues compared to those of noncancerous tissues, and high miR-125b expression indicated a poor prognosis in breast cancer patients. Tang et al demonstrated that upregulation of miR-125b was able to activate the metastatic activities of breast cancer cells in vivo and in vitro by inducing breast cancer cells to obtain epithelial and mesenchymal characteristics while regulating the reorganization of actin cytoskeleton through the STARD13-Ras homologue gene family member A-Rho-associated protein kinase signaling pathway (13). Consistently, the present results showed that miR-125b expression was correlated with clinical TNM stages. miR-125b-mediated breast cancer metastasis appears to account for the elevated stem cell-like side population and enhanced cancer stem cells properties (14). However, the upregulation of miR-125b is regulated by mechanisms that are not well understood in breast cancer. In B-cell progenitor acute lymphoblastic leukemia, translocation $\mathrm{t}(11 ; 14)(\mathrm{q} 24 ; \mathrm{q} 32)$ leads to a significant upregulation of miR-125b $(29,30)$. It is possible that chromosomal translocations may lead to aberrantly high miR-125b expression in breast and other types of tumors. Additional studies are required to determine the precise causes of aberrant miR-125b expression in cancer.

The present study additionally analyzed the association between miR-125b expression and ER, PR and HER2. miR-125b expression was positively correlated with HER2, but not ER and PR. Notably, high miR-125b expression was significantly correlated with tumor size and TNM 
Table II. Association between miR-125b expression and clinicopathological characteristics in breast cancer.

\begin{tabular}{|c|c|c|c|}
\hline \multirow[b]{2}{*}{ Variables } & \multicolumn{2}{|c|}{ miR-125b expression, $\mathrm{n}(\%)$} & \multirow[b]{2}{*}{ P-value } \\
\hline & High $($ score $\geq 1$ ) & Low (score <1) & \\
\hline Total & 151 & 70 & \\
\hline Age, mean $\pm \mathrm{SD}$ & $47.4 \pm 1.2$ & $45.9 \pm 0.8$ & 0.29 \\
\hline Gender & & & 1.00 \\
\hline Male & $1(100.0)$ & $0(0.0)$ & \\
\hline Female & $150(68.2)$ & $70(31.8)$ & \\
\hline Tumor size & & & 0.46 \\
\hline T1-T2 & 89 (70.6) & $37(29.4)$ & \\
\hline T3-T4 & $62(65.3)$ & $33(34.7)$ & \\
\hline Nodal metastasis & & & 0.23 \\
\hline Present & $121(70.3)$ & $51(29.7)$ & \\
\hline Absent & $30(61.2)$ & $19(38.8)$ & \\
\hline Distant metastasis & & & 0.26 \\
\hline Present & $15(57.7)$ & $11(42.3)$ & \\
\hline Absent & $136(69.7)$ & $59(30.3)$ & \\
\hline TNM stage & & & $0.02^{\mathrm{a}}$ \\
\hline I-II & $90(62.9)$ & $53(37.1)$ & \\
\hline III-IV & $61(78.2)$ & $17(21.8)$ & \\
\hline ER expression, n (\%) & & & 0.46 \\
\hline Positive & $84(66.1)$ & $43(33.9)$ & \\
\hline Negative & $67(71.3)$ & $27(28.7)$ & \\
\hline PR expression, n (\%) & & & 0.38 \\
\hline Positive & $82(65.1)$ & $44(34.9)$ & \\
\hline Negative & $69(72.6$ & $26(27.4)$ & \\
\hline \multicolumn{4}{|c|}{ HER2 expression, n (\%) } \\
\hline \multicolumn{4}{|l|}{$0.034^{\mathrm{a}}$} \\
\hline Positive & $105(73.4)$ & $38(26.6)$ & \\
\hline Negative & $46(59.0)$ & $32(41.0)$ & \\
\hline
\end{tabular}

${ }^{\mathrm{a}} \mathrm{P}<0.05$. SD, standard deviation; n, number; TNM, tumor-node-metastasis; ER, estrogen receptor; PR, progesterone receptor; HER2, human epidermal growth factor 2 ; miR, microRNA.

stages in HER2-positive breast cancer patients, along with a poor prognosis. Although studies have shown that HER2 is inversely correlated with miR-125b in gastric adenocarcinomas and ovarian cancer $(31,32)$, and acts as a target of miR-125b in small cell lung cancer (33) and endometrial cancer (34), there is no miR-125b-mediated downregulation of HER2 in miR-125b-transfected LNCaP and cds1 prostate cancer cells (35). Additionally our previous study did not identify downregulation of HER2 by miR-125b in breast cancer BT-474, BT-474M1 and SKBr3 cells (15). A reasonable explanation is that miRNAs exhibit their functions dependent on their diverse target genes in a cell type-specific and phenotype-specific manner (36). Due to the high heterogeneity of breast cancer, miR-125b may target different genes in various breast cancer cell lines. In addition, miR-125b can directly interact with the tumor suppressor gene p53, and target it in humans and zebrafish. Other molecules belonging to the p53 network such as Bak1, puma and cell cycle regulators are also targeted by miR-125b (37). Thus, miR-125b can interfere with oncogenic signaling by inhibiting key components of the p53 network, acting as an oncogenic miRNA.

In addition, miR-125b also plays a role in chemoresistance in breast cancer. It was previously found that overexpression of miR-125b caused a marked inhibition of paclitaxel-induced apoptosis and increased resistance to paclitaxel by targeting Bak1 in breast cancer cells (15). The present study shows that high miR-125b expression is a marker of poor prognosis in breast cancer patients that are treated with paclitaxel. Wang et al (16) showed that high miR-125b expression had an increased percentage of proliferating cells and decreased percentage of apoptotic cells subsequent to neoadjuvant chemotherapy in breast cancer patients, and reducing the miR-125b level sensitized breast cancer cells to chemotherapy. Previously, Vilquin et al (38) demonstrated that ectopic overexpression of miR-125b is sufficient to confer MCF-7 cell resistance to letrozole and anastrozole 
Table III. Association between miR-125b expression and clinicopathological characteristics in HER2-positive breast cancer.

\begin{tabular}{|c|c|c|c|}
\hline \multirow[b]{2}{*}{ Variables } & \multicolumn{2}{|c|}{ miR-125b expression, $\mathrm{n}(\%)$} & \multirow[b]{2}{*}{ P-value } \\
\hline & High (score $\geq 1$ ) & Low (score <1) & \\
\hline Total, n & 105 & 38 & \\
\hline Age, mean \pm SD & $46.7 \pm 1.06$ & $48.2 \pm 1.86$ & 0.49 \\
\hline \multicolumn{4}{|l|}{ Gender } \\
\hline Male & $0(0.0)$ & $0(0.0)$ & 1.00 \\
\hline Female & $105(73.4)$ & $38(26.6)$ & \\
\hline Tumor size & & & $0.03^{\mathrm{a}}$ \\
\hline $\mathrm{T} 1-2$ & $59(67.0)$ & $29(33.0)$ & \\
\hline T3-4 & $46(83.6)$ & 9 (16.4) & \\
\hline Nodal metastasis & & & $0.03^{\mathrm{a}}$ \\
\hline Present & $88(77.9)$ & $25(22.1)$ & \\
\hline Absent & $17(56.7)$ & $13(43.3)$ & \\
\hline Distant metastasis & & & 0.72 \\
\hline Present & $9(69.2)$ & $4(30.8)$ & \\
\hline Absent & $96(73.8)$ & $34(26.2)$ & \\
\hline TNM stage & & & $0.02^{\mathrm{a}}$ \\
\hline I-II & $57(66.3)$ & $29(33.7)$ & \\
\hline III-IV & $48(84.2)$ & $9(15.8)$ & \\
\hline
\end{tabular}

${ }^{\mathrm{a}} \mathrm{P}<0.05$. HER2, human epidermal growth factor; SD, standard deviation; TNM, tumor-node-metastasis; miR, microRNA.

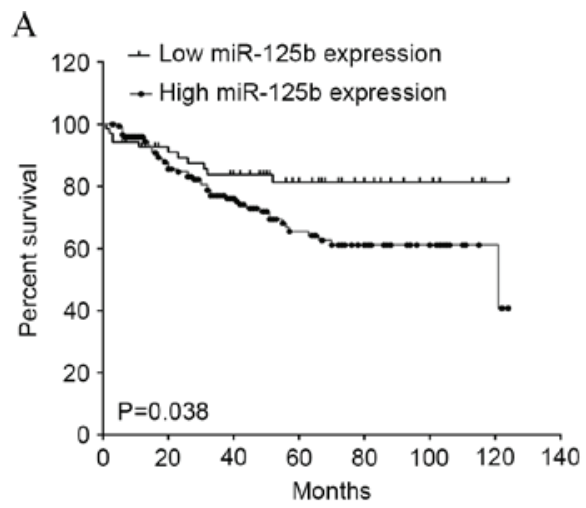

B

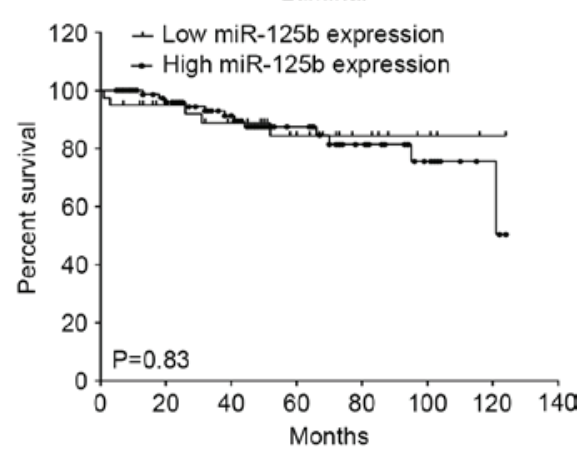

C

HER2

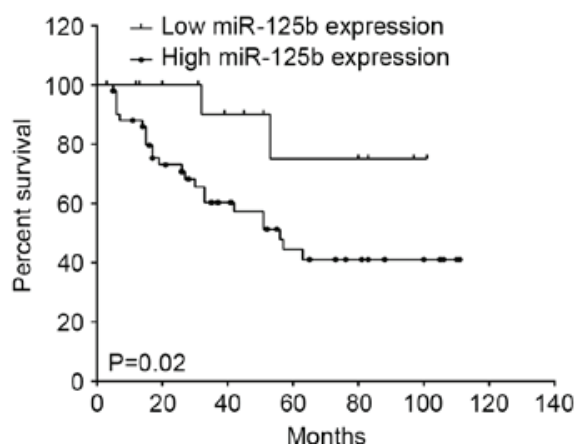

$\mathrm{D}$

TNBC

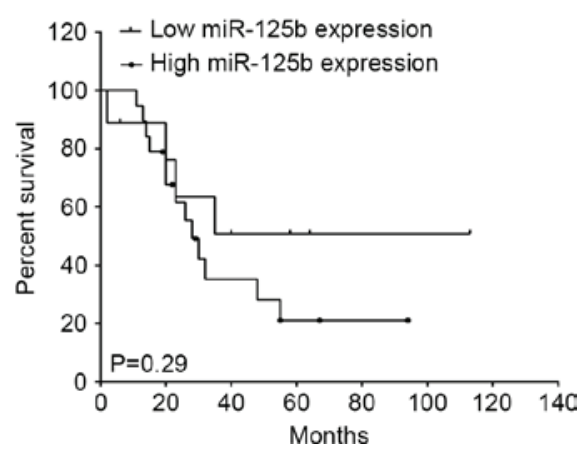

Figure 3. Kaplan-Meier overall survival curves of breast cancer patients and their expression of miR-125b. Kaplan-Meier analysis plotting the survival curve of 221 cases of breast cancer with the expression of miR-125b and clinicopathological characteristics with statistical significance being assessed using the log-rank test. (A) Kaplan-Meier curves showed worse overall survival rates for breast cancer patients with low miR-125b expression compared to patients with high miR-125b expression ( $\mathrm{P}=0.038)$. (B) Patients with high or low miR-125b expression had comparable overall survival rates in the luminal subtype $(\mathrm{P}=0.83)$. (C) Patients with high miR-125b expression had significant lower overall survival rates than those with low miR-125b expression in the HER2 subtype ( $\mathrm{P}=0.02)$. (D) Patients with high miR-125b expression had a slight but not significant lower overall survival rate compared to those with low miR-125b expression in TNBC subtype ( $\mathrm{P}=0.29)$. HER2, human epidermal growth factor 2; TNBC, triple-negative breast cancer; miR, microRNA. 


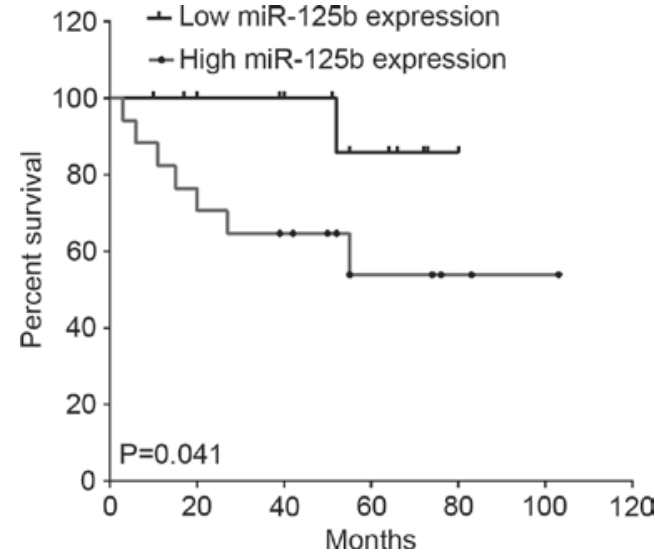

Figure 4. Kaplan-Meier overall survival curves of breast cancer patients treated with paclitaxel and their expression of miR-125b. Kaplan-Meier curves showed worse overall survival rates for breast cancer patients treated with paclitaxel with high miR-125b expression compared to patients with low miR-125b expression $(\mathrm{P}=0.041)$. miR, microRNA.

by targeting and activating the AKT/mammalian target of rapamycin pathway, which appears to be estrogen-independent. In addition, elevated miR-125b expression levels are a novel marker for poor prognosis in letrozole resistant breast cancer. Furthermore, elevated miR-125b levels in circulation may be a marker for early breast cancer detection (7). Clinically, elevated expression of miR-125b is associated with non-pathological complete response in breast cancer patients that received taxane-anthracycline-based neoadjuvant chemotherapy (39).

Overall, the present study provides evidence that elevated miR-125b expression predicts a poor prognosis, as well as a poor clinical responsiveness of paclitaxel-based neoadjuvant chemotherapy, and is associated with tumor size and TNM stage in HER2-positive breast cancer. Thus, identification of miR-125b may be a potential molecular biomarker for prediction of the clinical outcome in breast cancer patients, particularlyHER2-positive cases that receive paclitaxel-based neoadjuvant chemotherapy.

\section{Acknowledgements}

This study was supported by grants obtained from the National Natural Science Foundation of China (grant nos. 81328019 and 81572748) and the Natural Science Foundation of Hunan Province (grant no. 2015JJ2148).

\section{References}

1. Torre LA, Bray F, Siegel RL, Ferlay J, Lortet-Tieulent J and Jemal A: Global cancer statistics, 2012. CA Cancer J Clin 65: 87-108, 2015.

2. Eroles P, Bosch A, Pérez-Fidalgo JA and Lluch A: Molecular biology in breast cancer: Intrinsic subtypes and signaling pathways. Cancer Treat Rev 38: 698-707, 2012.

3. Goldhirsch A, Wood WC, Coates AS, Gelber RD, Thürlimann B and Senn HJ; Panel members: Strategies for subtypes-dealing with the diversity of breast cancer: Highlights of the St. Gallen international expert consensus on the primary therapy of early breast cancer 2011. Ann Oncol 22: 1736-1747, 2011.

4. Byler S, Goldgar S, Heerboth S, Leary M, Housman G, Moulton K and Sarkar S: Genetic and epigenetic aspects of breast cancer progression and therapy. Anticancer Res 34: 1071-1077, 2014.
5. Kontorovich T, Levy A, Korostishevsky M, Nir U and Friedman E: Single nucleotide polymorphisms in miRNA binding sites and miRNA genes as breast/ovarian cancer risk modifiers in Jewish high-risk women. Int J Cancer 127: 589-597, 2010.

6. Baffa R, Fassan M, Volinia S, O'Hara B, Liu CG, Palazzo JP, Gardiman M, Rugge M, Gomella LG, Croce CM and Rosenberg A: MicroRNA expression profiling of human metastatic cancers identifies cancer gene targets. J Pathol 219: 214-221, 2009.

7. Matamala N, Vargas MT, Gonzalez-Campora R, Minambres R, Arias JI, Menendez P, Andres-Leon E, Gomez-Lopez G, Yanowsky K, Calvete-Candenas J, et al: Tumor microRNA expression profiling identifies circulating microRNAs for early breast cancer detection. Clin Chem 61: 1098-1106, 2015.

8. Banzhaf-Strathmann J and Edbauer D: Good guy or bad guy: The opposing roles of microRNA $125 \mathrm{~b}$ in cancer. Cell Commun Signal 12: 30, 2014

9. Ferracin M,BassiC,Pedriali M,Pagotto S,D'Abundo L,ZagattiB, Corrà $\mathrm{F}$, Musa $\mathrm{G}$, Callegari $\mathrm{E}$, Lupini L, et al: miR-125b targets erythropoietin and its receptor and their expression correlates with metastatic potential and ERBB2/HER2 expression. Mol Cancer 12: 130, 2013.

10. Zhang Y, Yan LX, Wu QN, Du ZM, Chen J, Liao DZ, Huang MY, Hou JH, Wu QL, Zeng MS, et al: miR-125b is methylated and functions as a tumor suppressor by regulating the ETS1 proto-oncogene in human invasive breast cancer. Cancer Res 71: 3552-3562, 2011.

11. Feliciano A, Castellvi J, Artero-Castro A, Leal JA, Romagosa C, Hernandez-Losa J, Peg V, Fabra A, Vidal F, Kondoh H, et al: miR-125b acts as a tumor suppressor in breast tumorigenesis via its novel direct targets ENPEP, CK2- $\alpha$, CCNJ, and MEGF9. PLoS One 8: e76247, 2013.

12. Scott GK, Goga A, Bhaumik D, Berger CE, Sullivan CS and Benz CC: Coordinate suppression of ERBB2 and ERBB3 by enforced expression of micro-RNA miR-125a or miR-125b. J Biol Chem 282: 1479-1486, 2007.

13. Tang F, Zhang R, He Y,Zou M, Guo L and Xi T: MicroRNA-125b induces metastasis by targeting STARD13 in MCF-7 and MDA-MB-231 breast cancer cells. PLoS One 7: e35435, 2012.

14. Wang HJ, Guo YQ, Tan G, Dong L, Cheng L, Li KJ, Wang ZY and Luo HF: miR-125b regulates side population in breast cancer and confers a chemoresistant phenotype. J Cell Biochem 114: 2248-2257, 2013

15. Zhou M, Liu Z, Zhao Y, Ding Y, Liu H, Xi Y, Xiong W, Li G, Lu J, Fodstad O, et al: MicroRNA-125b confers the resistance of breast cancer cells to paclitaxel through suppression of pro-apoptotic Bcl-2 antagonist killer 1 (Bak1) expression. J Biol Chem 285: 21496-21507, 2010.

16. Wang H, Tan G, Dong L, Cheng L, Li K, Wang Z and Luo H: Circulating MiR-125b as a marker predicting chemoresistance in breast cancer. PLoS One 7: e34210, 2012.

17. Fan SQ, Ma J, Zhou J, Xiong W, Xiao BY, Zhang WL, Tan C, Li XL, Shen SR, Zhou M, et al: Differential expression of Epstein-Barr virus-encoded RNA and several tumor-related genes in various types of nasopharyngeal epithelial lesions and nasopharyngeal carcinoma using tissue microarray analysis. Hum Pathol 37: 593-605, 2006.

18. Sorlie T, Tibshirani R, Parker J, Hastie T, Marron JS, Nobel A, Deng S, Johnsen H, Pesich R, Geisler S, et al: Repeated observation of breast tumor subtypes in independent gene expression data sets. Proc Natl Acad Sci USA 100: 8418-8423, 2003.

19. Calin GA, Sevignani C, Dumitru CD, Hyslop T, Noch E, Yendamuri S, Shimizu M, Rattan S, Bullrich F, Negrini M, et al: Human microRNA genes are frequently located at fragile sites and genomic regions involved in cancers. Proc Natl Acad Sci USA 101: 2999-3004, 2004.

20. Nakanishi H, Taccioli C, Palatini J, Fernandez-Cymering C, Cui R, Kim T, Volinia S and Croce CM: Loss of miR-125b-1 contributes to head and neck cancer development by dysregulating TACSTD2 and MAPK pathway. Oncogene 33: 702-712, 2014.

21. Henson BJ, Bhattacharjee S, O'Dee DM, Feingold E and Gollin SM: Decreased expression of miR-125b and miR-100 in oral cancer cells contributes to malignancy. Genes Chromosomes Cancer 48: 569-582, 2009.

22. Liu LH, Li H, Li JP, Zhong H, Zhang HC, Chen J and Xiao T: miR-125b suppresses the proliferation and migration of osteosarcoma cells through down-regulation of STAT3. Biochem Biophys Res Commun 416: 31-38, 2011. 
23. Smits M, Wurdinger T, van het Hof B, Drexhage JA, Geerts D, Wesseling P, Noske DP, Vandertop WP, de Vries HE and Reijerkerk A: Myc-associated zinc finger protein (MAZ) is regulated by miR-125b and mediates VEGF-induced angiogenesis in glioblastoma. FASEB J 26: 2639-2647, 2012.

24. He J, Xu Q, Jing Y, Agani F, Qian X, Carpenter R, Li Q, Wang XR, Peiper SS, Lu Z, et al: Reactive oxygen species regulate ERBB2 and ERBB3 expression via miR-199a/125b and DNA methylation. EMBO Rep 13: 1116-1122, 2012.

25. Bousquet M, Harris MH, Zhou B and Lodish HF: MicroRNA miR-125b causes leukemia. Proc Natl Acad Sci USA 107: 21558-21563, 2010.

26. Willimott $\mathrm{S}$ and Wagner SD: miR-125b and miR-155 contribute to BCL2 repression and proliferation in response to CD40 ligand (CD154) in human leukemic B-cells. J Biol Chem 287: 2608-2617, 2012.

27. Xia HF, He TZ, Liu CM, Cui Y, Song PP, Jin XH and Ma X: MiR-125b expression affects the proliferation and apoptosis of human glioma cells by targeting Bmf. Cell Physiol Biochem 23: 347-358, 2009.

28. Le MT, Teh C, Shyh-Chang N, Xie H, Zhou B, Korzh V, Lodish HF and Lim B: MicroRNA-125b is a novel negative regulator of $\mathrm{p} 53$. Genes Dev 23: 862-876, 2009.

29. Bousquet M, Quelen C, Rosati R, Mansat-De MV, La Starza R, Bastard C, Lippert E, Talmant P, Lafage-Pochitaloff M, Leroux D, et al: Myeloid cell differentiation arrest by miR-125b-1 in myelodysplastic syndrome and acute myeloid leukemia with the $\mathrm{t}(2 ; 11)(\mathrm{p} 21 ; \mathrm{q} 23)$ translocation. J Exp Med 205: 2499-2506, 2008.

30. Chapiro E, Russell LJ, Struski S, Cavé H, Radford-Weiss I, Valle VD, Lachenaud J, Brousset P, Bernard OA, Harrison CJ and Nguyen-Khac F: A new recurrent translocation $\mathrm{t}(11 ; 14)(\mathrm{q} 24 ; \mathrm{q} 32)$ involving IGH@ and miR-125b-1 in B-cell progenitor acute lymphoblastic leukemia. Leukemia 24: 1362-1364, 2010.

31. Fassan M, Pizzi M, Realdon S, Balistreri M, Guzzardo V, Zagonel V, Castoro C, Mastracci L, Farinati F, Nitti D, et al: The HER2-miR125a5p/miR125b loop in gastric and esophageal carcinogenesis. Hum Pathol 44: 1804-1810, 2013.
32. He J, Jing Y, Li W, Qian X, Xu Q, Li FS, Liu LZ, Jiang BH and Jiang Y: Roles and mechanism of miR-199a and miR-125b in tumor angiogenesis. PLoS One 8: e56647, 2013.

33. Yagishita S, Fujita Y, Kitazono S, Ko R, Nakadate Y, Sawada T, Kitamura Y, Shimoyama T, Maeda Y, Takahashi F, et al: Chemotherapy-regulated microRNA-125-HER2 pathway as a novel therapeutic target for trastuzumab-mediated cellular cytotoxicity in small cell lung cancer. Mol Cancer Ther 14: 1414-1423, 2015.

34. Shang C, Lu YM and Meng LR: MicroRNA-125b down-regulation mediates endometrial cancer invasion by targeting ERBB2. Med Sci Monit 18: BR149-BR155, 2012.

35. Shi XB, Xue L, Yang J, Ma AH, Zhao J, Xu M, Tepper CG, Evans CP, Kung HJ and deVere White RW: An androgen-regulated miRNA suppresses Bak1 expression and induces androgen-independent growth of prostate cancer cells. Proc Natl Acad Sci USA 104: 19983-19988, 2007.

36. Schwarzenbacher D, Balic M and Pichler M: The role of microRNAs in breast cancer stem cells. Int J Mol Sci 14: 14712-14723, 2013.

37. Le MT, Shyh-Chang N, Khaw SL, Chin L, Teh C, Tay J, O'Day E, Korzh V, Yang H, Lal A, et al: Conserved regulation of p53 network dosage by microRNA-125b occurs through evolving miRNA-target gene pairs. PLoS Genet 7: e1002242, 2011.

38. Vilquin P, Donini CF, Villedieu M, Grisard E, Corbo L, Bachelot T, Vendrell JA and Cohen PA: MicroRNA-125b upregulation confers aromatase inhibitor resistance and is a novel marker of poor prognosis in breast cancer. Breast Cancer Res 17: 13, 2015.

39. Zheng Y, Li S, Boohaker RJ, Liu X, Zhu Y, Zhai L, Li H, Gu F, Fan Y, Lang R, et al: A microRNA expression signature in taxane-anthracycline-based neoadjuvant chemotherapy response. J Cancer 6: 671-677, 2015. 